\title{
Prevalence and risk factors of low birth weight in Jos
}

\author{
1Yilgwan CS, 1Abok I I, 2Yinnang W D, Vajime B A
}

1Dept of Paediatrics,Jos University Teaching Hospital, (JUTH), 2Dept of Family Medicine, Plateau Specialist Hospital,Jos.

\begin{abstract}
This study examines the Prevalence and factors associated with low birthweight (LBW) in Jos.208 babies delivered by 208 women in Jos University Teaching Hospital, (JUTH) were studied over an eight week (12th February to 11th April 2003. A cross-sectional study was done and the sample gotten by systematic sampling of all the babies delivered.

Mean birth weight of the infants was $3.08 \pm 1.319$ (range 0.904 to 4.005 ) $\mathrm{kg}$. The prevalence of LBW was found to be $12.7 \%$. $L B W$ has bivariate associations with mother's educational status, height, and health problems during pregnancy, use of antenatal care facilities, and gestational age. No association was found between LBW and mother's occupation.

Although antenatal care provision is absolutely necessary, intervention approaches that go beyond clinical or primary care settings are also warranted for better nutrition of women. Concerted efforts in health and non-health sectors are necessary for improvement in health and social status of women in order to reduce low birthweight.
\end{abstract}

\section{Introduction}

In 1948, the first World Health Assembly adopted an international definition of prematurity as birth weight of 2,500 grams or less. 1 . It was however discovered that in developing countries the use of this standard resulted in an unusually high proportion of 'premature' babies most of whom were not born prematurely. The World Health Organization (WHO) then conducted a study on eighteen different countries at different stages of development. This revealed that babies could be classified into three main groups based on their birth weight and gestational age: small for gestational age, appropriate for age, large for age. Low birth weight was then defined as those babies weighing less than 2,500 grams within twenty four hours of birth. This group of babies can either be small for age or appropriate for age and they are usually at high risk of dying in their first twenty eight days of life from factors like hypoglycemia, sepsis, respiratory distress, prematurity etc. In Nigeria, neonatal death (death of an infant in the first twenty eight days of live) contributes about $25 \%$ of the total infant mortality with prematurity and low birth weight being the main contributor to these high neonatal deaths. 2

A reduction of at least one-third in the proportion of infants with low birth weight is one of the seven major goals for the current decade of the "A World Fit for Children" programme of the United Nations. Moreover, nutritional deprivation the major determinant of low birth weight - is a clear obstacle to the attainment of many of the Millennium Development Goals 1. Monitoring improvements in low birth weight is thus being given high priority within the UN system, as well as by national governments and the international nutrition community.

Although the significance and interpretation of low birth weight has recently been debated $3-5$, most experts agree that weight at birth is an indicator of a newborn's chances for survival, growth, long-term health and psychosocial development 6 . Babies whose birth weight is low as a result of undernourishment face a greatly increased risk of death during their first months and years of life $6-8$. The evidence also suggests that those children who do survive may be more likely to experience health problems throughout their lives; these include impaired cognitive development, as well as diabetes and coronary heart disease in adulthood 9, 10. Low birth weight in developing countries occurs primarily because of poor maternal health and nutrition. A variety of socioeconomic, medical, and psychosocial factors are known to increase the risk of low birth weight,69 but prevention programs aimed at primarily high-risk subgroups have been largely ineffective.

In addition, diseases such as diarrhoea, malaria and respiratory infections, which are common in many developing countries, can significantly impair fetal growth when women become infected during pregnancy 6,7 . In Nigeria just like in many developing countries, low birth weight is a significant contributor to the overall infant mortality rate and a major factor in the high neonatal mortality rate currently seen.2,11,12. An understanding of the prevalence and also the factors contributing and sustaining the problem will go a long way in addressing this significant cause of neonatal mortality with the aim of reducing it an attaining the Millennium development goals.

\section{Materials and Methods}

This prospective study was conducted at the labour room of the Jos University Teaching Hospital, Jos Nigeria. It is a 500-bed tertiary Hospital in north central Nigeria, whose 
referral area spans 6 of Nigeria's 36 states. It serves both as a secondary and a tertiary centre because of its peculiar location and costs being affordable to both the rich and poor. It serves as a training centre in neonatology for resident doctors in Paediatrics, and Obstetrics and Gynaecology, medical students as well post-basic nurses in midwifery and intensive care. For the purpose of this study, the following definitions were used: Low birth weight infant (LBW) as an infant whose birth weight is $<2500$ grams; Moderately Low birth weight infant (MLBW) as one whose birth weight is between 1500 to $<2500$ grams; Very Low birth Weight (VLBW) as an infant with birth weight between 1000 and $<1500$ grams; Extremely Low birth weight (ELBW) as an infant born with a weight $>500$ grams but $<1000$ grams, Preterm as an infant whose gestational age is less than thirty seven completed weeks.

All consecutive infants seen in the first 24 hours of life from February 2003 to April 2003 in the labour room of the Jos University Teaching Hospital, Jos, Nigeria were considered for recruitment. This period spanned the end of the dry season and the beginning of the rainy season. Parental consent was sought for and obtained prior to inclusion in the study. The maturity of these infants was determined, based on Dubowitz method, to be preterm, preterm SGA, Term or Term SGA. Age of mother and her parity were also recorded.Each baby was weighed unclothed with the BabyWeigh TM, electronic scale manufacture by MedelaR Inc. model 040.7012 . This machine has an accuracy rate of 0.034-0.042\%. Data was analysed using the EPI Info version 3.2.2

\section{RESULTS}

A total of 208 infants were eligible and all satisfied the inclusion criteria and so were recruited from February 12, 2003 to April 30, 2003. There were 103 males and 105 female infants $(M: F=1)$. During the same period, there were a total of $27 \mathrm{LBW}$ infants (10 Males: 17 Females) out of a total of 208 (M: F, 1:1.7) newborn infants seen in the unit. The LBW infants seen in the period were distributed as follows: ELBW 2 (7\%), VLBW 15 (55\%) and MLBW 10 $(37 \%)$.

\section{Characteristics of infants}

Mean birth weight of the infants was $3.08 \pm 1.319$ (range 0.904 to 4.005$) \mathrm{kg}$. The prevalence of LBW was found to be $12.7 \%$. When the birth weights were categorized, there were 2 (1\%) ELBW, 15 (7.2\%) VLBW and 10 (4.8\%) MLBW infants and $181(87 \%)$ were normal birth weight. (Table 1$)$. Majority of the LBW babies 20 (74\%) were term small-forgestational age infants, $5(25 \%)$ were preterm appropriatefor-gestational age and only 2 (7\%) were preterm small-forgestational age.

\section{Profile of mothers}

Most of the women whose infants were studied were in the age group 20-35 years (88\%) followed by women aged 35 years and above $(8.6 \%)$.Only three $(3.4 \%)$ of the women were less than 20 years of age. About $52 \%$ of the women were literate with a further $81 \%$ having had at least one antenatal care follow up visit.(Table 2)

Of the total number of low birth weight babies seen, 21 $(78 \%)$ of them were delivered by mothers in the age group 20 -35 years. No LBW baby was found among the babies of mothers less than 20 years of age.

\section{Distribution of birth weight according to risk factors}

Table 3 shows the results of testing the association of 7 factors found to influence LBW in previous studies. LBW has bivariate associations with mother's educational status, height, and health problems during pregnancy, use of antenatal care facilities, and gestational age. No association was found between LBW and mother's occupation. Only three variables reached the statistical significance level $(p<0.05)$ in the logistic regression multivariable model predicting low birth weight. Maternal height (OR 34.9, 95 per cent $\mathrm{CI}=7.70-79.47$ ), hypertension (OR 40.91,95 per cent $\mathrm{CI}=4.29-96.9$ ), and febrile illness in pregnancy (OR 4.81, 95 per cent $\mathrm{CI}=1.93-12.14)$.

\section{Discussion}

This study examined and analysed the prevalence and risk factors associated with LBW in a cross sectional study of birth cohort in JUTH labour room in Jos. LBW, found in 12.7 per cent of births in this study, is comparable to previous studies done in Nigeria by Ransome-Kuti12 and also falls within the range of 15 per cent to 30 per cent reported from South Asian countries such as India, Nepal and Sri Lanka13,14 and the figure reported by UNICEF and WHO for sub-Saharan Africa.

As expected, the factors that operate through maternal influences and pregnancy related pathways were more predictive given that they are most causally proximate to maternal health. Gestational

age, maternal height, and problems during pregnancy were predictive of LBW. It is generally acknowledged that etiology

of LBW is multifactorial, but the potential importance of any factor taken in isolation should be interpreted with caution as they are often interrelated. Recognition of the relative contribution of these predictive factors is required for appropriate allocation of limited resources and focused interventions in Nigeria.

Gestational age, especially pre-term birth, is most consistently associated with LBW. In developed countries, intra uterine growth retardation (IUGR) comprises one third of all LBW cases and pre-term accounts for the remainder two thirds, but reverse is true for less developed countries like Nigeria. The focus in less developed countries remains almost exclusively on LBW as it is considered to be one of the leading causes of stillbirths and perinatal mortality.1518

Accordingly, in our study, we found almost three quarters (74 per cent; $n=21$ ) of all LBW babies to be at-term deliveries, and 25 per cent of deliveries were pre-term $(<37$ weeks). However, extensive research is being conducted to determine factors associated with gestational age, especially pre-term births.

Antenatal care provision was significantly associated with LBW. However, based on our findings it is clear that provision of antenatal care and primary health care clinics is necessary, and it may be of relevance in reducing the burden of LBW. The modifiable risk factors that predict low birth weight pertain to the general health status of the mother including hypertension, febrile illness which could result from malaria with its attendant sequel of anemia. Thus, prevention of LBW requires intensive nutritional programs to improve the general health, weight status, and reduce 
anemia in women of reproductive age groups. Programs directed at girls and women much before pregnancy are needed. 19. Women and girl child education should be given the desired attention it deserves as it has been shown to strongly correlate with risk of LBW.

\section{References}

1.United Nations Administrative Committee on Coordination Subcommittee on Nutrition. Mainstreaming nutrition: opportunities to improve development outcomes. Fifth report on the world nutrition situation. Geneva: United Nations Administrative Committee on Coordination Subcommittee on Nutrition; 2004.

2. Grange A. Child survival in the twenty first century. A lecture presented at Paediatric Association of Nigeria Conference, Jos, 2006.

3. Wilcox AJ. On the importance - and the unimportance - of birthweight. International Journal of Epidemiology 2001;30:123341.

4. World Health Organization. Physical status: the use and interpretation of anthropometry. Geneva: WHO; 1995. WHO Technical Report Series, No. 854.

5. Osrin D, de L Costello AM. Maternal nutrition and fetal growth: practical issues in international health. Seminars in Neonatology 2000;5:209-19.

6. Bale JR, Stoll BJ, Lucas AO, editors. Improving birth outcomes: meeting the challenge in the developing world. Washington, DC: The National Academies Press; 2003.

7. United Nations Administrative Committee on Coordination Subcommittee on Nutrition. Nutrition throughout the life cycle. Fourth report on the world nutrition situation. Geneva: United Nations Administrative Committee on Coordination Subcommittee on Nutrition in collaboration with International Food Policy Research Institute; 2000.

8. Allen LH, Gillespie SR. What works? A review of the efficacy and effectiveness of nutrition interventions. Geneva: United Nations Administrative Committee on Coordination Subcommittee on Nutrition; 2001.

9. Bhargava SK, Sachdev HS, Fall CHD, Osmond C, Lakshmy R, Barker DJP, et al. Relation of serial changes in childhood bodymass index to impaired glucose tolerance in young adulthood. New England Journal of Medicine 2004;350:865-75.

10. Barker DJP. The developmental origins of adult disease.
Geneva; World Health Organization; 2003. Discussion paper for the WHO Expert Consultation towards the development of a strategy for promoting optimal fetal growth.

11. Boerma JT, Weinstein KI, Rutstein SO, Sommerfelt AE. Data on birth weight in developing countries: can surveys help? Bulletin of the World Health Organization 1996;74:209-16.

12. Ransome-Kuti O. Intra uterine Growth,Birth weight and maturity of the African newborn. Acta Paediatr Scand,1985, Suppl 319:95-102

13. Mavalankar DV, Trivedi CC, Gray RH. Maternal weight, height and risk of poor pregnancy outcome in Ahmedabad, India. Indian Pediatr 1994; 31: 1205-12.

14. World Health Organization. Multicenter study on Low Birth Weight and Infant Mortality in India,Nepal and Sri Lanka. Regional Health Paper,SEARO, No 25. New Delhi; 1994.

15. Kramer MS. Determinants of low birth weight:Methodological assessment and meta-analysis. Bull World Health Organ 1987;65: 663-37.

16. de Onis M, Blossner M, Villar J. Levels and patterns of intrauterine growth retardation in developing countries. Eur J Clin Nutr 1998; 52: S5-15.

17. Hosain GM. Stillbirth in a rural area of Bangladesh.Paper presented in the 11th Congress of the Federation of the Asia and Oceania Perinatal Societies. Manila,Philippines; 2000.

18. McDermott J, Steketee R, Wirima J. Perinatal mortality in rural Malawi. Bull World Health Organ 1996; 74:165-71.

19. Sable MR, Herman AA. The relationship between prenatal health behavior advice and low birth weight.Public Health Rep 1997; 112: 332-39. 